\title{
PENERAPAN ARTIFICIAL INTELLIGENCE PADA NON-PLAYER CHARACTER MENGGUNAKAN ALGORITMA COLLISION AVOIDANCE SYSTEM DAN RANDOM NUMBER GENERATOR PADA GAME 2D "BALAP EGRANG"
}

\author{
Asep Saeful Milak*1, Eka Wahyu Hidayat ${ }^{2}$, Aldy Putra Aldya ${ }^{3}$ \\ 1,2,3 Infomatika, Fakultas Teknik, Universitas Siliwangi \\ Email: ${ }^{1}$ asep.saepul.milak14@student.unsil.ac.id, ${ }^{2}$ ekawahyu@unsil.ac.id, ${ }^{3}$ aldy@unsil.ac.id \\ *Penulis Korespondensi
}

(Naskah masuk: 20 Februari 2019, diterima untuk diterbitkan: 07 Oktober 2020)

\begin{abstract}
Abstrak
Permainan Egrang merupakan salah satu permainan tradisional di Indonesia yang menggunakan bahan bambu sepanjang dua meter dan diberi pijakan dibawahnya. Permainan ini dapat dimainkan oleh semua umur dengan cara berpijak pada bagian pijakan dan menjaga keseimbangan saat berjalan dalam jarak dan waktu tertentu. Permainan ini sudah mulai tergerus zaman dan perlu dilakukan pelestarian. Penelitian ini mencoba untuk mengangkat kembali permainan tradisional kedalam game berbasis digital dengan menerapkan Artificial Intelligence. Game sejenis yang telah diobservasi, seperti Game Balap Karungs dari Playstore yang bergenre racing, memiliki kelemahan bersifat endless run dan juga tidak memiliki NPC (Non-Player Character). Hasil dari penelitian ini adalah permainan berbasis Android dengan menerapkan Algoritma Collision Avoidance System untuk membuat NPC dapat menghindari Obstacle dan Algoritma Random Number Generator untuk membuat Obstacle muncul secara acak. Pengembangan Game Balap Egrang ini menggunakan metode Game Development Life Cycle (GDLC). Berdasarkan pengujian yang telah dilakukan, hasil pengujian alpha sudah sesuai secara fungsional dan dari pengujian beta hasil uji fungsionalitas User Acceptence Test (UAT) didapat nilai sebesar 82,58\% dinyatakan layak untuk digunakan dengan interpretasi "Baik" yang berarti game ini layak digunakan dan dapat dikembangkan.
\end{abstract}

Kata kunci: Artificial Intelligence, Collision Avoidance System, Game, Obstacle, Random Number Generator

\section{APPLICATION OF ARTIFICIAL INTELLIGENCE IN NON-PLAYER CHARACTER USING COLLISION AVOIDANCE SYSTEM ALGORITHM AND RANDOM NUMBER GENERATOR IN 2D GAMES "EGRANG RACING"}

\begin{abstract}
Egrang game is one of the traditional games in Indonesia that uses two meters of bamboo material and is given a footing below. This game can be played by all ages by stepping on the footing and maintaining balance when walking at a certain distance and time. This game has begun to erode the era and needs to be preserved. This study tries to revive traditional games into digital-based games by implementing Artificial Intelligence. Similar games that have been observed, such as the Balap Karungs Game from Playstore which is in the racing genre, have endless run weaknesses and also have no Non-Player Character NPCs. The results of this study are Androidbased games by applying the Collision Avoidance System Algorithm to make NPCs avoid the Obstacle and Random Number Generator Algorithms to make the Obstacle appear randomly. The development of the Balap Egrang Game uses the Game Development Life Cycle (GDLC) method. Based on the tests that have been carried out, the alpha test results are functionally appropriate and from the beta testing the results of the User Acceptence Test (UAT) functionalities obtained a value of $82.58 \%$ which is declared feasible to use with the interpretation of "Good" which means that the game is feasible developed.
\end{abstract}

Keywords: Artificial Intelligence, Collision Avoidance System, Game, Obstacle, Random Number Generator

\section{PENDAHULUAN}

Permainan tradisional merupakan simbolisasi dari pengetahuan yang turun temurun dan mempunyai bermacam-macam fungsi atau pesan dibaliknya, permainan tradisional merupakan hasil budaya yang besar nilainya bagi anak-anak dalam rangka berfantasi, berekreasi, berkreasi, berolahraga yang sekaligus sebagai sarana berlatih untuk hidup bermasyarakat, keterampilan, kesopanan serta 
ketangkasan. Permainan tradisional dapat mengembangkan potensi setiap anak yang ditunjukkan dalam perilaku penyesuaian sosial dengan tetap melestarikan dan mencintai budaya bangsa (Andriani, 2012).

Permainan Egrang merupakan salah satu permainan tradisional di Indonesia yang memiliki berbagai nama di berbagai daerah. Permainan ini dulu sangat populer dan hampir diketahui di seluruh daerah. Permainan egrang yaitu permainan tradisional yang menggunakan bahan bambu sepanjang dua meter dan diberi pijakan $50 \mathrm{~cm}$ dari tanah, manfaat permainan egrang yaitu menjaga keseimbangan, kerja keras, keuletan, kreatifitas, keterampilan dan kecepatan (Hikmah, 2011), kenyataan yang ada sekarang permainan tradisional yang merupakan warisan budaya kini tidak lagi diminati, sangat sedikit anak-anak yang masih mengenal ataupun memainkan permainan tradisional. Penyebab sedikitya peminat permainan tradisional antara lain tergeser oleh permainan modern, ada mata rantai yang terputus dalam pewarisan permainan tradisional, makin terbatasnya lahan untuk bermain dan kehidupan modern yang makin individualistis (Wijaya, Purnawan, \& Wibawa, 2016).

Game atau permainan adalah sesuatu yang dapat dimainkan dengan aturan tertentu sehingga ada yang menang dan ada yang kalah, bermain game sudah dapat dikatakan sebagai life style masyarakat dimasa kini, dimulai dari usia anak - anak hingga orang dewasa pun menyukai video game, itu semua dikarenakan bermain video game adalah hal yang menyenangkan (Satriawan \& AlFatta, 2011).

Game berbasis kecerdasan buatan dikhususkan pada kemampuan komputer mengendalikan unsurunsur dalam game membuat keputusan cerdas ketika suatu kondisi memiliki beberapa pilihan dengan hasil akhir yang berbeda, sehingga menghasilkan perilaku yang relevan, efektif, dan berguna. Kecerdasan buatan dalam permainan sangat berorientasi pada hasil, dan dengan demikian, kita dapat mengatakan bahwa dunia game sangat berkaitan dengan perkembangan ilmu kecerdasan buatan (Troy, 2015).

Penerapan AI (Artificial Intelligence) dibutuhkan dalam sebuah game agar game lebih menarik, yang biasanya terdapat pada NPC (NonPlayer Character). NPC adalah karakter yang mampu berinteraksi dengan objek di dalam dunia game dan tindakannya tidak dapat dikendalikan oleh pemain, tindakan NPC yang tidak dapat diprediksi salah satunya adalah pergerakannya dari suatu tempat ketempat lain, dengan diterapkannya AI pada NPC sehingga membuat NPC mampu menemukan rute pergerakannya didalam game (Atthariq \& Putra, 2017).

Algoritma Collision Avoidance System adalah suatu algoritma yang berfungsi untuk melakukan suatu interaksi terhadap rintangan yang paling dekat kemudian menghindarinya yang di sisipkan kedalam Non-Player Character (NPC), Collision Avoidance
System bukan termasuk algoritma Path Finding yakni algoritma yang dapat membuat NPC bergerak menghindari rintangan (Obstacle) (Bevilacqua, 2013).

Algoritma Random Number Generator (RNG) adalah sebuah program atau alat untuk menghasilkan urutan angka atau simbol secara tidak teratur. Sistem ini diaplikasikan ke dalam banyak bidang, seperti sampel statistika, simulasi komputer, kriptografi, bahkan untuk desain (Hidayat, 2011).

Game bergenre racing sejenis seperti Balap Karungs dan Egrang Run dapat di download secara gratis dari Playstore. Hanya saja kedua game tersebut memiliki kekurangan yaitu bersifat endless run, tidak memiliki NPC (Non Player Character), tidak memiliki levelling dan tidak ada manfaat dari reward koin yang didapat. Selain itu, hanya game Balap Karungs saja yang memunculkan Obstacle pada saat dimainkan.

Berdasarkan latar belakang tersebut, maka dalam penelitian ini dirancang dan dibangun Game Balap Egrang berbasis 2D dan bergenre racing side scroller dengan menerapkan AI didalamnya. Penelitian ini berfokus pada pengembangan Game yang menerapkan Algoritma Collision Avoidance System dan Random Number Generator sebagai AI (Artificial Intelligence) pada NPC (Non-Player Character) yang berfungsi untuk menghindari rintangan (obstacle) yang ada.

Rumusan masalah yang menjadi pokok dalam penelitian ini yaitu, bagaimana merancang dan membangun Game 2D "Balap Egrang" Pada Platform Android, bagaimana menerapkan AI (Artificial Intelligence) untuk NPC (Non-Player Character) untuk menghindari rintangan (Obstacle) dan munculnya Obstacle secara acak pada game 2D "Balap Egrang", serta bagaimana menguji algoritma Collision Avoidance System dan Random Number Generator yang digunakan dalam Game Balap Egrang.

Tujuan yang ingin dicapai dalam penelitian ini yaitu, merancang dan membangun game 2D "Balap Egrang" berplatform Android menggunakan metode GDLC (Game Development Life Cycle), menerapkan AI (Artificial Intelligence) untuk NPC (Non-Player Character) menggunakan algoritma Collision Avoidance System dan Random Number Generator untuk menghindari rintangan (Obstacle) dan munculnya Obstacle secara acak pada game 2D "Balap Egrang" serta menguji Algoritma Collision Avoidance System dan Random Number Generator yang digunakan dalam Game Balap Egrang.

\section{METODE PENELITIAN}

Metode penelitian yang digunakan dalam penelitian ini menggunakan metode Design and Creation (Oates, 2006) yang terdiri dari tahapan yaitu Awareness, Suggestion, Development, Evaluation dan Conclusion. Tahap Awareness melakukan perumusan masalah dalam melakukan penelitian 
yaitu dengan cara studi pustaka dan observasi. Tahap Suggestion melakukan pemberian saran untuk solusi dari permasalahan yang sudah didapat dalam tahap sebelumnya dan membuat rancangan konsep untuk menyelesaikan masalah dalam penelitian. Tahap Development merupakan tahap pengembangan yang dilakukan dalam Rekayasa produk multimedia dalam penelitian ini mengacu pada metodologi GDLC (Game Development Life Cycle) (Ramadan, 2013) metode ini terdiri dari Initiation, Pre-Production, Production, Testing, Beta dan Release. Tahap Evaluation melakukan evaluasi hasil dari penelitian yang sudah dilakukan sesuai dengan permasalahan dan tujuan yang diusulkan dalam penelitian. Tahap Conclusion melakukan masukan untuk ide pengembangan selanjutnya dari kekurangan yang sudah dibuat untuk peneliti atau pengembang selanjutnya, dan juga memberikan kesimpulan dari hasil penelitian yang sudah dilakukan. Adapun skema dari tahapan diatas digambarkan dalam diagram metode penelitian sebagai berikut:

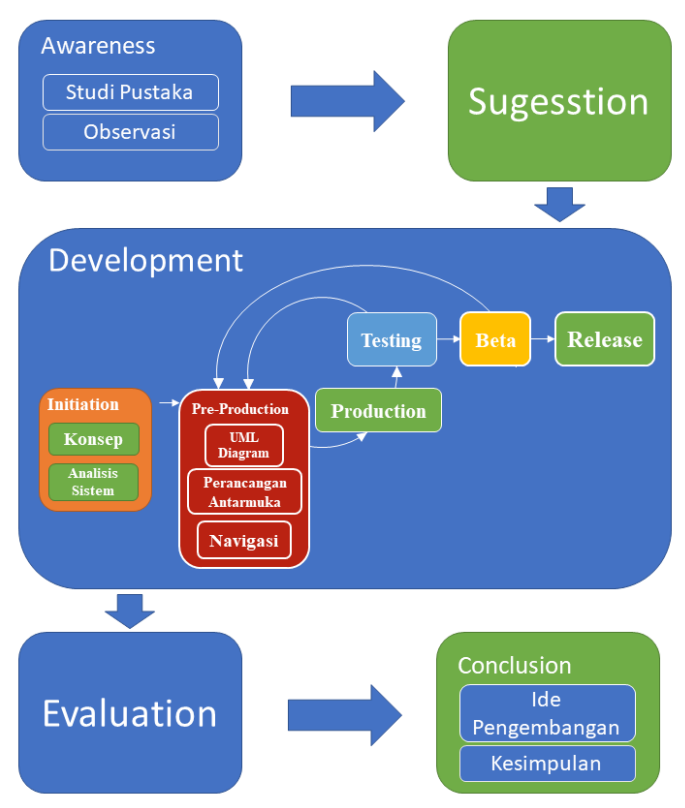

Gambar 1. Metodologi Penelitian

\subsection{Initiation}

Tahapan melakukan gambaran konsep untuk pengembangan game "Balap Egrang" yang dikembangkan dan dibangun berdasarkan ide yang ada, untuk menentukan tujuan, mengidentifikasi pengguna, jenis produk, dasar aturan, ukuran, dan target.

\subsection{Pre-Production}

Tahapan ini dilakukan secara rinci mulai dari gambaran awal produk seperti apa, mulai dari arsitektur aplikasi, antarmuka aplikasi, serta elemen pendukung lainnya, tahapan ini dapat mempengaruhi atau menjadi acuan untuk tahapan selanjutnya.
Tabel 1. Deskripsi Konsep

\begin{tabular}{ll}
\hline Konsep & Keterangan \\
\hline Judul & Balap Egrang \\
Audiens & Umum \\
Durasi & Tidak terbatas \\
Animasi & Animasi karakter 2D (*.PNG) \\
Audio & Instrumen (*.MP3) \\
Image & Gambar, Icon, Button (*.PNG dan *.JPG) \\
Teks & Tulisan pada setiap menu, perintah dan \\
& petunjuk game \\
Interaktifitas & Tombol \\
Tema & Racing, Side Scroller \\
Karakter & Terdapat 3 Karakter \\
Deskripsi & Game ini merupakan game racing dengan \\
Aplikasi & menggunakan egrang sebagai alat yang \\
& diperlombakannya \\
& berkompetisi dengan karakter musuh sampai \\
& garis akhir dan juga memiliki level yang \\
& berbeda dan juga tempat yang berbeda. \\
\hline \multicolumn{1}{c}{ Scene } & Tabel 2. Story Board Ringkas \\
\hline Scene 1 & Tampilan Menu Utama \\
Scene 2 & Tampilan Pilih Level \\
Scene 3 & Tampilan Gameplay Balap Egrang \\
Scene 4 & Tampilan Menu Options \\
Scene 5 & Tampilan Informasi Cara Bermain \\
Scene 6 & Tampilan Tentang Aplikasi \\
\hline & \\
\hline & \\
\hline &
\end{tabular}

Rancangan tampilan menggunakan Screen Design Worksheet (SDW) yang berisi rancangan tampilan aplikasi, tombol navigasi dan keterangan dari rancangan objek yang dibuat. Sedangkan untuk menggambarkan sistem secara keseluruhan menggunakan pendekatan UML seperti gambar dibawah ini.

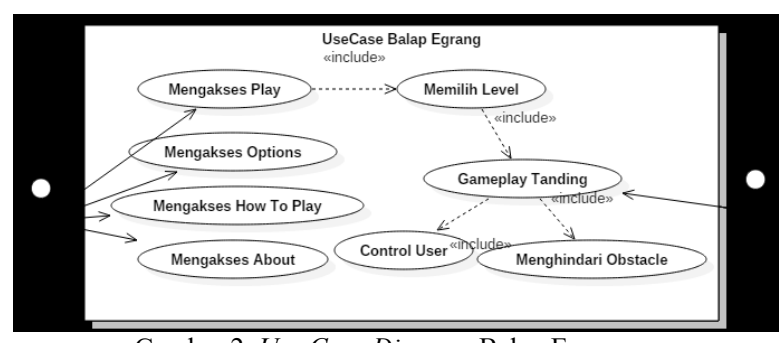

Gambar 2. Use Case Diagram Balap Egrang

Untuk struktur navigasi, model interaksi pengguna menggunakan Struktur Navigasi Hirarki, dimana penelusuran dilakukan mulai dari level tertinggi ke level dibawahnya secara hirarki.

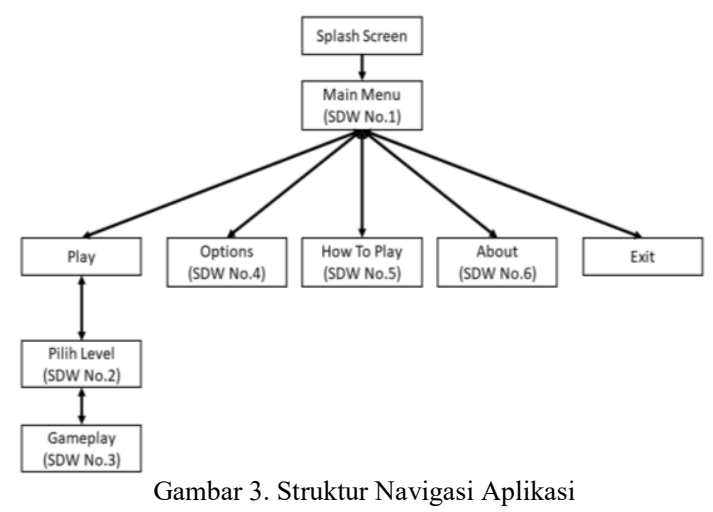




\subsection{Production}

Tahapan ini merupakan tahapan inti dari proses pengembangan Game yang meliputi pembuatan objek, kode program dan penggabungan keduanya menjadi sebuah produk multimedia berupa Game "Balap Egrang".

\section{Objek 2 Dimensi}

Karakter 2 Dimensi digunakan sebagai objek Player dan juga NPC yang terdiri dari 1 objek untuk Player dan 2 objek untuk NPC, karakter terdiri dari beberapa gerakan dalam 1 gambar dengan format file *.PNG yang nantinya digabungkan untuk pembuatan animasi tiap karakter.

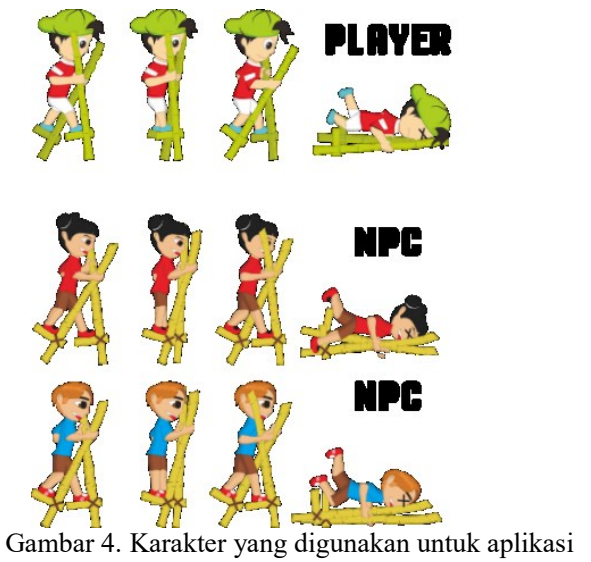

2. Pembuatan Sound Effect

Pembuatan dan juga pengumpulan sound effect difungsikan untuk menambahkan suara pada game agar terlihat lebih menarik, dibuat dengan menggunakan aplikasi FL Studio dan juga mengambil beberapa asset dari internet yang berlisensi gratis, suara ini digunakan pada setiap menu yang ada pada game "Balap Egrang" seperti menu utama, options, how to play, about, pilih level dan gameplay.

3. Pembuatan User Interface

Pembuatan user interface ini ditunjukan untuk mengimplementasikan rancangan antar muka yang diterapkan pada aplikasi yang dibuat, design user interface menggunkan aplikasi pengolah gambar yaitu Adobe Photoshop CC 2014.

4. Pembuatan Kode Program

Pembuatan kode program untuk pembuatan game "Balap Egrang" dengan menggunakan Bahasa pemograman $\mathrm{CH}$, proses penulisan kode program menggunakan aplikasi Visual Studio 2017, terdapat beberapa program yang dibuat mulai dari perpindahan layer, control karakter, pergerakan NPC, unlock level, kode untuk menghindari rintangan, kode program posisi.

Implementasi algoritma Collision Avoidance System diimplementasikan dalam sebuah program yang dimasukkan kedalam karakter NPC yang berfungsi untuk mencari Obstacle yang ada di jalurnya kemudian menghindari Obstacle tersebut, proses penentuan karakter NPC untuk menghindari
Obstacle menggunakan parameter Collider yaitu sebuah batasan antara objek agar tidak terjadi tubrukan.

\begin{tabular}{|c|c|}
\hline Program & Analisis \\
\hline 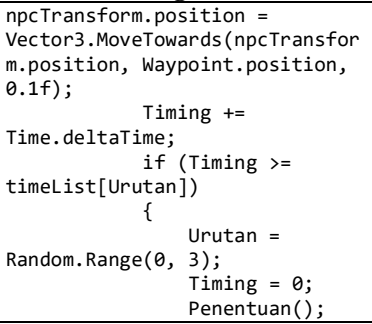 & $\begin{array}{l}\text { Program penentuan } \\
\text { pergerakan NPC mulai dari } \\
\text { kecepatan gerak dan proses } \\
\text { penentuan untuk pencarian } \\
\text { Obstacle (Penentuan). }\end{array}$ \\
\hline $\begin{array}{l}\text { void Penentuan( }) \\
\text { if(Obstacle }==\text { false) } \\
\quad\{\text { Lurus }() ; \\
\quad\} \\
\text { else } \\
\left\{\begin{array}{l}\text { Miring }() ; \\
\}\end{array}\right.\end{array}$ & $\begin{array}{l}\text { Program penentuan untuk } \\
\text { menghindari Obstacle } \\
\text { dengan parameter Collider, } \\
\text { jika didepan tidak ada } \\
\text { Obstacle maka berjalan } \\
\text { lurus sedangkan kalo ada } \\
\text { Obstacle berjalan miring } \\
\text { atau menghindari } \\
\text { Obstacle. }\end{array}$ \\
\hline 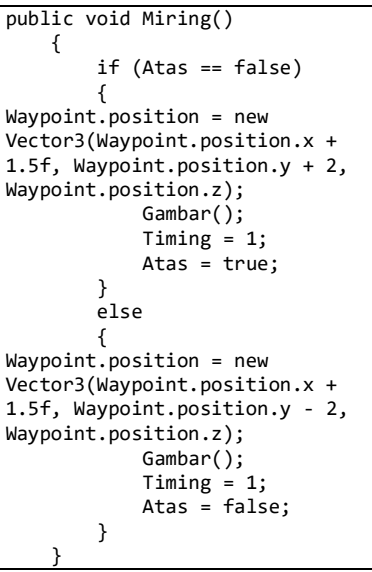 & $\begin{array}{l}\text { Program penentuan } \\
\text { pergerakan NPC untuk } \\
\text { menghindari Obstacle, jika } \\
\text { NPC berada diatas (Atas = } \\
\text { true) maka ketika ada } \\
\text { Obstacle dijalurnya NPC } \\
\text { akan menghindar ke bawah } \\
\text { dengan pengubahan posisi } \\
\text { x dan y, sedangkan kalau } \\
\text { NPC berada di bawah } \\
\text { (Atas=false) maka ketika } \\
\text { ada Obstacle NPC akan } \\
\text { menghindari ke atas } \\
\text { dengan pengubahan posisi } \\
\text { x dan y. }\end{array}$ \\
\hline
\end{tabular}

Implementasi Algoritma Random Number Generator dimplementasikan dalam sebuah kode program yang berfungsi untuk menampilkan Obstacle secara acak pada setiap level yang dimainkan dalam game "Balap Egrang", kode program menggunakan parameter Random Range yakni pengacakan pada posisi tertentu yang sudah ditentukan sebelumnya.

Tabel 4. Hasil Analisis Algoritma Random Number Generator

\begin{tabular}{|c|c|}
\hline Program & Analisis \\
\hline $\begin{array}{l}\text { void Start }() \\
\left\{\begin{array}{l}\text { ( }) \\
\text { Urutan }=\text { Random. Range }(\theta,\end{array}\right. \\
\text { 3); }\end{array}$ & $\begin{array}{l}\text { Program penentuan } \\
\text { munculnya Obstacle } \\
\text { dengan Random Range }\end{array}$ \\
\hline $\begin{array}{l}\quad \text { transform.position }=\text { new } \\
\text { Vector3(transform.position.x, } \\
\text { PosisiY[Urutan], } \\
\text { transform.position.z); } \\
\quad \text { \} }\end{array}$ & $\begin{array}{l}\text { dan pengubahan } \\
\text { penempatan pada posisi Y } \\
\text { sesuai urutan antara } 1-3 \text {. }\end{array}$ \\
\hline
\end{tabular}

5. Pembuatan Game

Tahapan penggabungan semua elemen multimedia seperti teks, gambar, suara dan animasi yang sudah dibuat sebelumnya, semua elemen tersebut digabungkan kedalam Software Unity untuk tahap pembuatan Game Balap Egrang. 


\section{HASIL DAN PEMBAHASAN}

\subsection{Antarmuka Game Balap Egrang}

Hasil dari pembuatan game yang telah dilakukan pada tahapan Production menghasilkan antarmuka sebagai berikut:

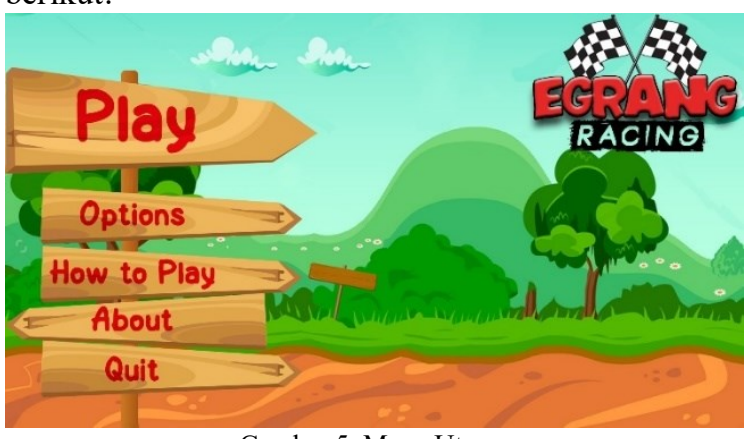

Gambar 5. Menu Utama

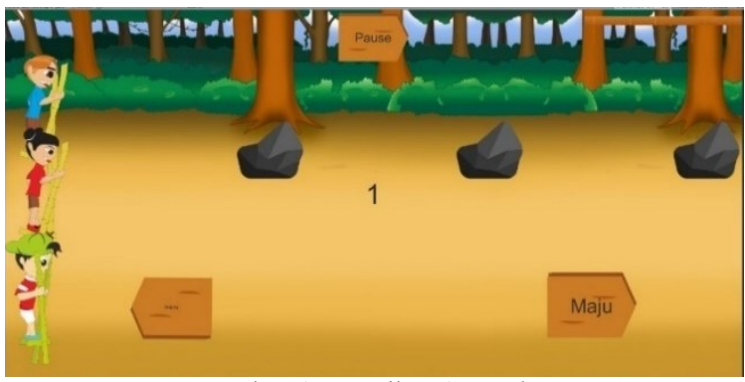

Gambar 6. Tampilan Gameplay

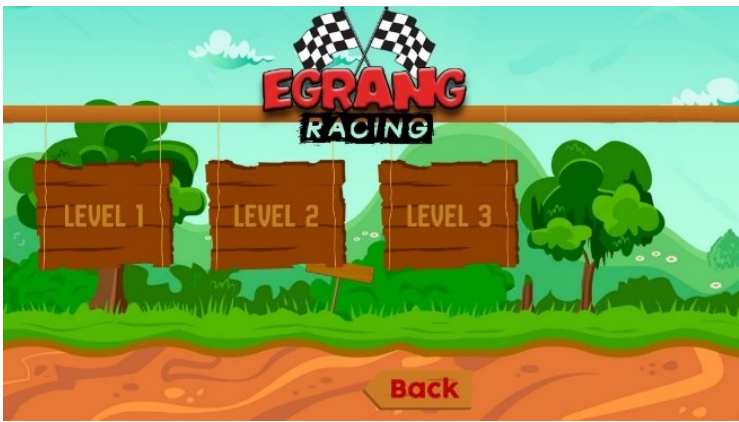

Gambar 7. Tampilan Menu Pilih Level

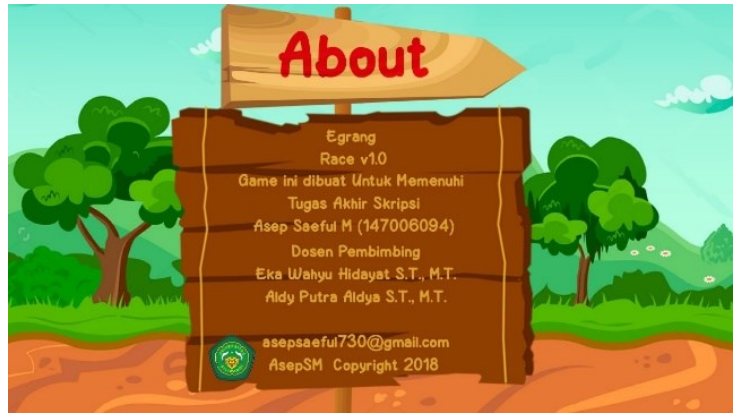

Gambar 8. Tampilan Menu About

\subsection{Alpha Testing}

Tahapan ini merupakan tahap selanjutnya setelah production dilakukan yaitu tahap testing atau pengujian game yang sudah dibuat untuk melihat kemungkinan adanya kesalahan, tahap ini dilakukan dengan metode Alpha test untuk menguji aplikasi secara fungsional dan pengujian algoritma, dilanjutkan dengan Beta test untuk mendapatkan feedback dari pengguna.

Tahapan Pengujian Alpha Test menggunakan metode black-box testing. Metode black-box digunakan untuk mengetahui apakah game berfungsi dengan benar, pengujian fungsional dilakukan untuk menguji tampilan Menu Utama, Pilih Level, Gameplay, Menu Options, Menu How to play dan Menu About. Hasil dari pengujian tersebut secara fungsi sudah sesuai dan dapat diterima. Untuk pengujian Menu Utama dapat dilihat pada 989able berikut ini:

\begin{tabular}{|c|c|c|c|}
\hline No & $\begin{array}{l}\text { Skenario } \\
\text { Pengujian }\end{array}$ & $\begin{array}{l}\text { Hasil yang } \\
\text { diharapkan }\end{array}$ & Respon Aplikasi \\
\hline 1 & $\begin{array}{l}\text { Tombol } \\
\text { navigasi } \\
\text { Permainan } \\
\text { Utama }\end{array}$ & $\begin{array}{l}\text { Menampilkan } \\
\text { permainan } \\
\text { utama dari } \\
\text { game "Balap } \\
\text { Egrang" }\end{array}$ & $\begin{array}{l}\text { Perpindahan scene } \\
\text { dari menu utama ke } \\
\text { menu gameplay } \\
\text { berhasil berjalan } \\
\text { dengan lancar }\end{array}$ \\
\hline 2 & $\begin{array}{l}\text { Tombol } \\
\text { navigasi } \\
\text { Options }\end{array}$ & $\begin{array}{l}\text { Menampilkan } \\
\text { pengaturan } \\
\text { untuk } \\
\text { mengubah suara } \\
\text { dalam game }\end{array}$ & $\begin{array}{l}\text { Perpindahan scene } \\
\text { dari menu utama ke } \\
\text { menu Options } \\
\text { berhasil berjalan } \\
\text { dengan lancar }\end{array}$ \\
\hline 3 & $\begin{array}{l}\text { Tombol } \\
\text { navigasi } \\
\text { How to } \\
\text { play }\end{array}$ & $\begin{array}{l}\text { Menampilkan } \\
\text { tutorial cara } \\
\text { bermain game } \\
\text { "Balap Egrang" }\end{array}$ & $\begin{array}{l}\text { Perpindahan scene } \\
\text { dari menu utama ke } \\
\text { menu How to Play } \\
\text { berhasil berjalan } \\
\text { dengan lancar }\end{array}$ \\
\hline 4 & $\begin{array}{l}\text { Tombol } \\
\text { navigasi } \\
\text { About }\end{array}$ & $\begin{array}{l}\text { Menampilkan } \\
\text { informasi } \\
\text { tentang game }\end{array}$ & $\begin{array}{l}\text { Perpindahan scene } \\
\text { dari menu utama ke } \\
\text { menu About berhasil } \\
\text { berjalan dengan } \\
\text { lancar }\end{array}$ \\
\hline 5 & $\begin{array}{l}\text { Tombol } \\
\text { navigasi } \\
\text { Pilih } \\
\text { Level }\end{array}$ & $\begin{array}{l}\text { Menampilkan } \\
\text { level yang } \\
\text { tersedia dalam } \\
\text { game Balap } \\
\text { Egrang }\end{array}$ & $\begin{array}{l}\text { Perpindahan scene } \\
\text { dari Pilih level ke } \\
\text { scene level yang } \\
\text { dipilih berhasil } \\
\text { berjalan dengan } \\
\text { lancar }\end{array}$ \\
\hline 6 & $\begin{array}{l}\text { Judul } \\
\text { Game }\end{array}$ & $\begin{array}{l}\text { Menampilkan } \\
\text { judul game } \\
\text { "Balap Egrang" }\end{array}$ & $\begin{array}{l}\text { Informasi judul } \\
\text { berhasil ditampilkan } \\
\text { dengan baik. }\end{array}$ \\
\hline
\end{tabular}

Selanjutnya melakukan pengujian Algoritma Collision Avoidance System. Pengujian Algoritma ini dilakukan untuk mengetahui hasil apakah algoritma yang dipakai pada NPC bisa melewati Obstacle yang berada pada lintasan, pengujian ini melakukan metode analisis kualitatif dengan membandingkan NPC 1 dan NPC 2 dalam melewati Obstacle ketika dalam berbeda jalur dengan jalur yg sama antara NPC, dengan Hasil yang ada pada Tabel 6 .

Hasil dari tabel diatas dilakukan beberapa percobaan didalam Game untuk menguji Algoritma Collision Avoidance System yang diterapkan pada Kedua NPC yang awalnya mempunyai jalur masingmasing pada lintasan, hasil dari percobaan bahwa Algoritma berjalan dengan baik dalam menghindari Obstacle, tapi ada percobaan yang membuat NPC tidak menghindar atau bahkan menembus Obstacle yakni ketika NPC1 dan NPC2 berada dalam jalur yang sama dan saling rapat maka salah satu saja yang dapat menghindar sedangkan yang satu lagi akan menembus NPC, hal tersebut disebabkan karena 
Algoritma yang dipakai menggunakan Parameter Collider jadi algoritma tidak bisa membaca 2 Collider secara bersamaan.

\begin{tabular}{|c|c|c|c|c|}
\hline \multirow[b]{2}{*}{$\begin{array}{c}\text { Percobaan } \\
\text { Ke- }\end{array}$} & \multicolumn{2}{|c|}{ NPC 1} & \multicolumn{2}{|c|}{ NPC 2} \\
\hline & $\begin{array}{c}\text { Posisi } \\
\text { NPC } \\
2\end{array}$ & Status & $\begin{array}{l}\text { Posisi } \\
\text { NPC } 1\end{array}$ & Status \\
\hline 1.1 & $\begin{array}{l}\text { Beda } \\
\text { Jalur }\end{array}$ & Ke bawah & $\begin{array}{l}\text { Beda } \\
\text { Jalur }\end{array}$ & $\begin{array}{l}\text { Tidak Ada } \\
\text { Obstacle }\end{array}$ \\
\hline 1.2 & $\begin{array}{l}\text { Satu } \\
\text { Jalur }\end{array}$ & $\mathrm{Ke}$ atas & $\begin{array}{l}\text { Satu } \\
\text { Jalur }\end{array}$ & $\begin{array}{l}\text { Menembus } \\
\text { Obstacle }\end{array}$ \\
\hline 1.3 & $\begin{array}{l}\text { Beda } \\
\text { Jalur }\end{array}$ & Ke bawah & $\begin{array}{l}\text { Beda } \\
\text { Jalur }\end{array}$ & $\begin{array}{l}\text { Tidak Ada } \\
\text { Obstacle }\end{array}$ \\
\hline 2.1 & $\begin{array}{l}\text { Beda } \\
\text { Jalur }\end{array}$ & Ke Bawah & $\begin{array}{l}\text { Beda } \\
\text { Jalur }\end{array}$ & $\begin{array}{l}\text { Tidak Ada } \\
\text { Obstacle }\end{array}$ \\
\hline 2.2 & $\begin{array}{l}\text { Satu } \\
\text { Jalur }\end{array}$ & Ke atas & $\begin{array}{l}\text { Satu } \\
\text { Jalur }\end{array}$ & $\begin{array}{l}\text { Menembus } \\
\text { Obstacle }\end{array}$ \\
\hline 2.3 & $\begin{array}{l}\text { Beda } \\
\text { Jalur }\end{array}$ & Ke bawah & $\begin{array}{l}\text { Beda } \\
\text { Jalur }\end{array}$ & $\begin{array}{l}\text { Tidak Ada } \\
\text { Obstacle }\end{array}$ \\
\hline 3.1 & $\begin{array}{l}\text { Beda } \\
\text { Jalur }\end{array}$ & Ke Bawah & $\begin{array}{l}\text { Beda } \\
\text { Jalur }\end{array}$ & $\begin{array}{l}\text { Tidak Ada } \\
\text { Obstacle }\end{array}$ \\
\hline 3.2 & $\begin{array}{l}\text { Satu } \\
\text { Jalur }\end{array}$ & Ke atas & $\begin{array}{l}\text { Satu } \\
\text { Jalur }\end{array}$ & ke atas \\
\hline 4.1 & $\begin{array}{l}\text { Beda } \\
\text { Jalur }\end{array}$ & $\begin{array}{l}\text { Tidak Ada } \\
\text { Obstacle }\end{array}$ & $\begin{array}{l}\text { Beda } \\
\text { Jalur }\end{array}$ & ke Atas \\
\hline 4.2 & $\begin{array}{l}\text { Satu } \\
\text { Jalur }\end{array}$ & $\begin{array}{l}\text { Menembus } \\
\text { Obstacle }\end{array}$ & $\begin{array}{l}\text { Satu } \\
\text { Jalur }\end{array}$ & $\begin{array}{l}\text { Menembus } \\
\text { Obstacle }\end{array}$ \\
\hline 4.3 & $\begin{array}{l}\text { Satu } \\
\text { Jalur }\end{array}$ & Ke Bawah & $\begin{array}{l}\text { Satu } \\
\text { Jalur }\end{array}$ & ke bawah \\
\hline 4.4 & $\begin{array}{l}\text { Satu } \\
\text { Jalur }\end{array}$ & Ke Atas & $\begin{array}{l}\text { Satu } \\
\text { Jalur }\end{array}$ & ke Atas \\
\hline 5.1 & $\begin{array}{l}\text { Beda } \\
\text { Jalur }\end{array}$ & ke bawah & $\begin{array}{l}\text { Beda } \\
\text { Jalur }\end{array}$ & $\begin{array}{l}\text { Tidak Ada } \\
\text { Obstacle }\end{array}$ \\
\hline 5.2 & $\begin{array}{l}\text { Satu } \\
\text { Jalur }\end{array}$ & Ke Atas & $\begin{array}{l}\text { Satu } \\
\text { Jalur }\end{array}$ & $\begin{array}{l}\text { Menembus } \\
\text { Obstacle }\end{array}$ \\
\hline 5.3 & $\begin{array}{l}\text { Beda } \\
\text { Jalur }\end{array}$ & $\begin{array}{l}\text { Tidak Ada } \\
\text { Obstacle }\end{array}$ & $\begin{array}{l}\text { Beda } \\
\text { Jalur }\end{array}$ & Ke atas \\
\hline
\end{tabular}

Kesimpulannya Algoritma Collision Avoidance System berhasil diterapkan pada NPC dan berhasil menghindari Obstacle dengan catatan tiap NPC tidak saling berdempetan.

Tahapan terakhir pengujian adalah pengujian Algoritma Random Number Generator. Pengujian Algoritma ini dilakukan untuk mengetahui hasil apakah algoritma yang dipakai berhasil membuat posisi Obstacle secara acak, pengujian ini dilakukan dalam game langsung untuk mengetahui Algoritma bekerja dengan baik atau tidak, algoritma ini memiliki parameter perubahan posisi $\mathrm{Y}$ dari 0 sampai 4 dengan menggunakan Random Range, hasil dari pengujian terdapat pada tabel 7 sebagai berikut:

Tabel 7. Pengujian Algoritma Random Generator Number

\begin{tabular}{ccccccccc}
\hline \multirow{2}{*}{$\begin{array}{c}\text { Percobaan } \\
\text { Ke- }\end{array}$} & $\mathbf{1}$ & $\mathbf{2}$ & $\mathbf{3}$ & $\mathbf{4}$ & $\mathbf{5}$ & $\mathbf{6}$ & $\mathbf{7}$ & $\mathbf{8}$ \\
\cline { 2 - 9 } & 0 & 2 & 2 & 0 & 0 & 0 & 0 & 4 \\
2 & 2 & 4 & 4 & 0 & 0 & 4 & 0 & 4 \\
3 & 2 & 0 & 2 & 4 & 0 & 2 & 0 & 2 \\
4 & 0 & 0 & 0 & 4 & 4 & 2 & 2 & 2 \\
5 & 0 & 2 & 2 & 2 & 2 & 0 & 0 & 4 \\
6 & 4 & 4 & 2 & 4 & 2 & 4 & 0 & 0 \\
\hline
\end{tabular}

Hasil dari tabel pengujian diatas pengujian dilakukan pada 8 Obstacle yang ada pada tiap lintasan dan dilakukan percobaan sebanyak 6 kali, menunjukan bahwa Obstacle akan muncul secara acak pada setiap percobaan. Kesimpulannya bahwa Algoritma Random Number Generator berhasil diterapkan pada Obstacle yang membuat muncul secara acak.

\subsection{Beta Testing}

Pengujian Beta ini dilakukan pengambilan data dengan menggunakan metode survey berupa pengisian kuisioner kepada pengguna akhir. Tujuan dari penyebaran kuisioner ini untuk mendapatkan umpan balik dari pengguna yang memainkan game yang dibuat, kuisioner menggunakan pendekatan VISUALS dengan perhitungan menggunakan metode Skala Likert (Sugiyono, 2013). Rancangan pertanyaan-pertanyaan pada kuesioner dengan pendekatan VISUALS, Materi-materi yang terkumpul disajikan dengan bahasa yang sederhana dan komunikatif dilengkapi dengan komponenkomponen multimedia lainnya dengan memperhatikan konsep VISUALS (Hidayat \& Irawan, 2013), yaitu, Visible atau mudah dilihat, yaitu materi yang disajikan secara visual terlihat jelas, tingkat keterbacaan tinggi, resolusi atau ketajaman grafis tinggi, mengandung satu makna. Interesting atau menarik, yaitu isi pesan sesuai dengan kebutuhan audien, tampilan baik dan memikat sehingga menimbulkan rasa ingin tahu, dan berusaha menjaga kelangsungan proses komunikasi atau interaksi dan belajar. Simple atau sederhana, yaitu pesan terfokus, pemilihan kata, huruf, gambar tidak mengubah makna pesan, bahasa dan tampilan lugas. Useful atau berguna, yaitu sesuai dengan kebutuhan audien dan tujuan pembelajaran maupun hasil belajar yang diinginkan. Accurate atau tepat, yaitu isi pesan mempunyai makna yang tepat, sesuai dengan kebutuhan, penyampaiannya cermat, didasarkan pada sumber yang dapat di pertanggung jawabkan. Legitimate atau benar, yaitu isi pesan benar, disusun secara logis, mengikuti kaidah keilmuan, dan masuk akal. Structure atau terstruktur, yaitu rangkaianpesan disampaikan secara sistematis, dengan urutan-urutan yang logis dan mudah dipahami.

Proses beta testing dengan kuisioner yang disebar kepada responden, populasi yang diambil adalah orang yang pernah atau giat dalam bermain game, sedangkan sampel yang telah diambil berjumlah 30 orang, Kemudian persentase dari masing-masing jawaban kuesioner diidentifikasi dengan menggunakan rumus Skala Likert (Sugiyono, 2013) sebagai berikut:

\section{Rumus Interval}

$$
\begin{array}{r}
\text { Hasil }=T \times P x \ldots . . .(1) \\
\text { Index }=\frac{\text { Jumlah }}{Y} \times 100 \ldots . . .(2) \\
\mathbf{I}=\mathbf{1 0 0} / \text { Jumlah skor (likert) }
\end{array}
$$

$\mathrm{I}=100 / 3$

$\mathrm{I}=33,33 \%$ 
Keterangan:

$T \quad=$ hasil responden

$P x \quad=$ jumlah skor likert

$Y \quad=$ skor tertinggi likert

Total responden yang mengisi kuesioner sebanyak 30 orang. Berikut adalah persentase hasil pengolahan kuesioner seperti pada Tabel 8.

\begin{tabular}{|c|c|c|c|c|c|c|}
\hline Aspek & Soal & B & $\mathrm{C}$ & $\mathbf{K}$ & Skor & Presentase \\
\hline \multirow[t]{4}{*}{ Visible } & 1 & 81 & 6 & 0 & 87 & $96,67 \%$ \\
\hline & 2 & 63 & 18 & 0 & 81 & $90,00 \%$ \\
\hline & 3 & 45 & 30 & 0 & 75 & $83,33 \%$ \\
\hline & 4 & 57 & 22 & 0 & 79 & $87,78 \%$ \\
\hline \multirow[t]{3}{*}{ Interesting } & 5 & 42 & 32 & 0 & 74 & $82,22 \%$ \\
\hline & 6 & 54 & 24 & 0 & 78 & $86,67 \%$ \\
\hline & 7 & 66 & 16 & 0 & 82 & $91,11 \%$ \\
\hline \multirow[t]{3}{*}{ Simple } & 8 & 54 & 24 & 0 & 78 & $86,67 \%$ \\
\hline & 9 & 81 & 6 & 0 & 87 & $96,67 \%$ \\
\hline & 10 & 48 & 28 & 0 & 76 & $84,44 \%$ \\
\hline \multirow[t]{2}{*}{ Useful } & 11 & 69 & 14 & 0 & 83 & $92,22 \%$ \\
\hline & 12 & 42 & 32 & 0 & 74 & $82,22 \%$ \\
\hline \multirow[t]{4}{*}{ Accurate } & 13 & 48 & 28 & 0 & 76 & $84,44 \%$ \\
\hline & 14 & 36 & 36 & 0 & 72 & $80,00 \%$ \\
\hline & 15 & 36 & 36 & 0 & 72 & $80,00 \%$ \\
\hline & 16 & 24 & 42 & 1 & 67 & $74,44 \%$ \\
\hline \multirow[t]{4}{*}{ Legitimate } & 17 & 63 & 18 & 0 & 81 & $90,00 \%$ \\
\hline & 18 & 72 & 12 & 0 & 84 & $93,33 \%$ \\
\hline & 19 & 36 & 36 & 0 & 72 & $80,00 \%$ \\
\hline & 20 & 72 & 12 & 0 & 84 & $93,33 \%$ \\
\hline \multirow[t]{2}{*}{ Structrure } & 21 & 60 & 20 & 0 & 80 & $88,89 \%$ \\
\hline & 22 & 60 & 20 & 0 & 80 & $88,89 \%$ \\
\hline Jumlah & & \multicolumn{4}{|c|}{ Skor : $1635 / 22=\mathbf{7 4 , 3 1}$} & $\begin{array}{c}1816,67 \% / 22= \\
\mathbf{8 2 , 5 8 \%}\end{array}$ \\
\hline
\end{tabular}

Tabel 9. Nilai Interval Persentase Skala likert

\begin{tabular}{cc}
\hline Persentase & Kriteria \\
\hline $0 \%-33,32 \%$ & Kurang \\
$33,33 \%-66,65 \%$ & Cukup \\
$66,66 \%-100 \%$ & Baik \\
\hline
\end{tabular}

Kesimpulan yang bisa diambil hasil dari kuisioner menunjukan kategori tingkat validasi diatas, maka dapat disimpulkan bahwa game ini memiliki interpretasi 'Baik', sehingga dapat dikatakan game ini layak untuk digunakan.

Aplikasi ini memiliki kelebihan dan kekurangan Kelebihan aplikasi "Balap Egrang" yaitu Konsep Game mengacu pada permainan tradisional yaitu Egrang, Penambahan NPC pada gameplay membuat Balap Egrang lebih realistis, Penambahan System Leveling membuat tingkatan bermain lebih susah dan tidak monoton. Terdapat rintangan (Obstacle) yang muncul secara acak yang menambah tingkat kesulitan game. Sedangkan kekurangan dari aplikasi "Balap Egrang" yaitu Game tidak bisa dimainkan secara multiplayer, Game tidak bisa berjalan dibawah OS Android Jelly Bean, Game hanya tersedia 3 Level, NPC tidak dapat melewati Obstacle ketika NPC menempel dengan NPC lain.

\subsection{Release}

Tahapan ini merupakan tahapan terakhir dalam proses pembuatan produk multimedia, hasil pada penelitian ini menghasilkan sebuah produk multimedia yakni berupa game yang bergenre racing yaitu "Balap Egrang" (Egrang Race: The Beginning). Produk ini didistribusikan pada Playstore dan bisa di unduh secara gratis.

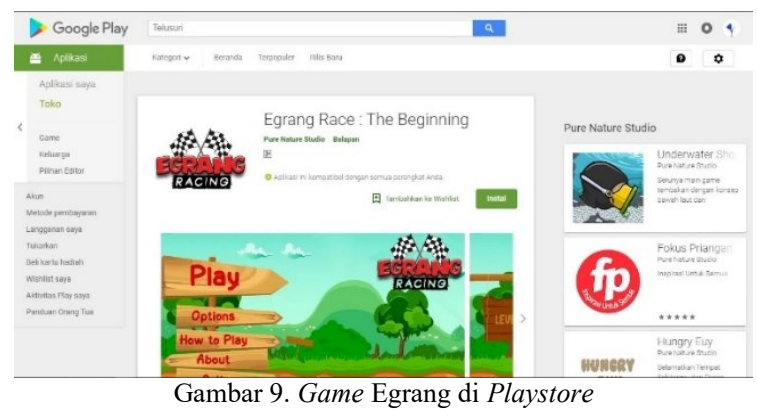

\section{KESIMPULAN}

Berdasarkan hasil penelitian yang telah dilakukan dapat diambil kesimpulan yaitu, telah berhasil dirancang dan dibangun Game Balap Egrang dengan menggunakan Metode GDLC (Game Development Life Cycle) yang dapat berjalan diperangkat smartphone Android, yang memberikan pengalaman baru dalam bermain game Racing karena mengangkat permainan tradisional yaitu Egrang dengan menerapkan Algoritma Collision Avoidance System pada AI NPC untuk menghindari Obstacle dan Algoritma Random Number Generator untuk memunculkan rintangan secara acak. Hasil pengujian terhadap Algoritma Collision Avoidance System yang diterapkan berhasil membuat NPC menghindari Obstacle dan hasil pengujian terhadap Algoritma Random Number Generator berhasil membuat Obstacle muncul secara acak.

Saran untuk aplikasi ini yaitu Aplikasi lebih menarik apabila ditambahkan lebih banyak karakter dan ditambah fitur kostumisasi karakter, seperti perubahan tampilan Egrang nya, Menambahkan level dan tingkatan kesulitan dalam Game Balap Egrang, Karakter dalam Game diubah menjadi 3 Dimensi (3D) agar lebih realistis, dapat dimainkan secara multiplayer, dapat menyempurnakan pergerakan NPC dalam menghindari Obstacle dengan algoritma $\mathrm{A}^{*}$ (A Star)

\section{DAFTAR PUSTAKA}

ANDRIANI, T., 2012. Permainan Tradisional Dalam Membentuk Karakter Anak Usia Dini. Jurnal Sosial Budaya, Vol. 9 No. 1.

ATTHARIQ, A., DAN PUTRA, D.A., 2017. Penentuan Pergerakan Non-Player Character Menggunakan Algoritma A* Pada Game Action- Role-Playing Game. Jurnal Infomedia Vol. 2 No. 2 Desember 2017, pp.35-40.

BEVILACQUA, F., 2013. Game Development Programming: Understanding Steering Behaviors: Collision Avoidance. 
https://gamedevelopment.tutsplus.com/tutor ials/understanding-steering-behaviorscollision-avoidance--gamedev-7777, [Diakses : 12 Januari 2019]

HIDAYAT, E.W., DAN IRAWAN, E. P., 2013. Prototype Informasi Digital Jurusan Teknik Informatika UNSIL Berbasis Multimedia. STMIK BUMIGORA MATARAM : ISBN : 978-602-17488-0-0.

HIDAYAT, T.R., 2011. Random Number Generator. Makalah IF2091 Struktur Diskrit, pp.1-5.

HIKMAH, M., 2011 Perancangan Game Tradisional Jawa Egrang Bambu. Mulok Perpustakaan UM, pp.1-3.

OATES, B. J., 2006. Researching Information Systems and Computing, SAGE Publications, London, ISBN:1-4129-02231, pp.108-124.

RAMADAN, R., DAN WIDYANI, R., 2013. Game Development Life Cycle Guidelines. ICACSIS 2013, ISBN: 978-979-1421-19-5, pp.95-100.

SATRIAWAN, A., DAN FATTA, H.A., 2011. Game Edukasi Baby Lost in The Jungle dengan Adobe Flash Cs3. Jurnal Data Manajemen dan Teknologi Informasi, Vol. 12 No. 4 Desember 2011, pp.42-45.

SUGIYONO, S., 2013. Metode Penelitian Pendidikan Pendekatan Kuantitatif, Kualitatif, dan R\&D. Bandung: Alfabeta.

TROY, T., 2015. Tinjauan Historis Kecerdasan Buatan Dalam Games. Journal of Animation and Games Studies Vol. 1 No. 2 Oktober 2015, pp.135-164.

WIJAYA, A.A.M.A., PURNAWAN, I.K.A. \& WIBAWA, K.S., 2016. Rancang Bangun Game Tajog Race Berbasis Android. Merpati Vol. 4 No. 2 Agustus 2016, ISSN: 2252-3006, pp.166-177. 